\title{
Cuidado de enfermagem na relação saber/poder e sexualidade junto a juventude escolar via webrádio
}

Nursing care in the relationship knowledge / power and sexuality with school youth via webrádio Atención de enfermería en la relación conocimiento / poder y sexualidad con jóvenes escolares a través de webrádio

\section{Leidy Dayane Paiva de Abreu ${ }^{\mathrm{I}}$, Glícia Mesquita Martiniano Mendonça ${ }^{\mathrm{II}}$, Aretha Feitosa de Araújo $^{\mathrm{III}}$, Raimundo Augusto Martins Torres ${ }^{\mathrm{IV}}$, Maria Rocineide Ferreira da Silvav ${ }^{\mathrm{V}}$, Ana Virgínia de Melo FialhovI}

Resumo: Objetivo: descrever a experiência de pós-graduandas de enfermagem sobre a sexualidade e a relação saber-poder junto à juventude escolar via WebRádio. Método: a experiência emergiu na disciplina de "Micropolítica", realizada no primeiro semestre de 2016, em articulação ao referencial teórico-filosófico Saber/Poder de Foucault e a temática da sexualidade. Resultados: na vivência é visto que a escola e o setor saúde se configuram como espaços de resistência. Há ausência de discurso professor(a)/enfermeiro(a)/juventude sobre a sexualidade. Culminou-se que o dispositivo de cuidado em saúde WebRádio é uma rede interdiscursiva, com envolvimento das singularidades, proporcionando práticas de cuidado junto à juventude. Considerações finais: A enfermagem, nesse cenário escolar, amplia sua autonomia de cuidado junto à juventude na construção de saberes interdiscursivos.

Descritores: Enfermagem; Jovens; Sexualidade; Tecnologias digitais

Abstract: Objective: To describe the experience of postgraduate nursing students about sexuality and the knowledge-power relationship with school youth via WebRódio. Method: the experience emerged in the discipline of "Micropolitics", held in the first semester of 2016, in articulation with Foucault's Knowledge / Power theoretical

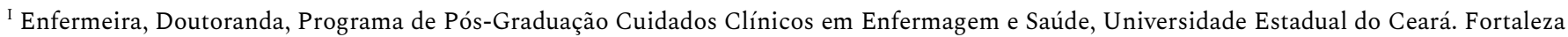
(CE), Brasil. Email: dayannepaiva@hotmail.com ORCID https://orcid.org/0000-0001-8895-1481

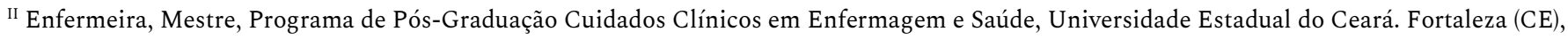
Brasil. Email: glicia_martiniano@hotmail.com ORCID https://orcid.org/0000-0003-2535-2080 https://orcid.org/0000-0003-2535-2080

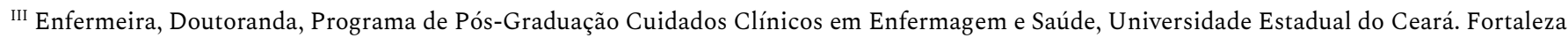
(CE), Brasil. Docente da Faculdade de Juazeiro do Norte (CE) Email: aretha.feitosa@gmail.com ORCID https://orcid.org/0000-0001-9297-8281

IV Enfermeiro, Doutor em Educação, Docente do Curso de Enfermagem da Universidade Estadual do Ceará(UECE). Fortaleza(CE), Brasil. Email: augustomtorres70@gmail.com ORCID https://orcid.org/0000-0002-8114-4190

${ }^{\vee}$ Enfermeira, Doutora em Saúde Coletiva, Docente do Curso de Enfermagem da Universidade Estadual do Ceará(UECE). Fortaleza(CE), Brasil. Email: rocineideferreira@gmail.com ORCID https://orcid.org/0000-0002-6086-6901

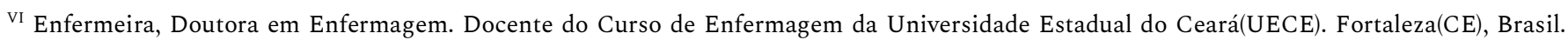
Email: anavirginiamf@terra.com.br ORCID https://orcid.org/0000-0002-4471-1758
} 
and philosophical framework and the theme of sexuality. Results: in the experience it is seen that the school and the health sector are configured as spaces of resistance. There is an absence of teacher / nurse / youth speech about sexuality. It was concluded that the WebRadio health care device is an interdiscursive network, involving singularities, providing care practices to the youth. Final considerations: Nursing, in this school setting, expands its autonomy of care with the youth in the construction of interdiscursive knowledge.

Descriptors: Nursing; Young; Sexuality; Digital technologies

Resumen: Objetivo: Describir la experiencia de los estudiantes de posgrado de enfermería sobre sexualidad y la relación conocimiento-poder con los jóvenes escolares a través de WebRódio. Método: la experiencia surgió en la disciplina de "Micropolítica", realizada en el primer semestre de 2016, en articulación con el marco teórico y filosófico de Foucault Knowledge / Power y el tema de la sexualidad. Resultados: en la experiencia se ve que la escuela y el sector salud están configurados como espacios de resistencia. Hay una ausencia de discurso del maestro / enfermera / joven sobre la sexualidad. Se concluyó que el dispositivo de atención médica WebRadio es una red interdiscursiva, que involucra singularidades y brinda prácticas de atención a los jóvenes. Consideraciones finales: La enfermería, en este entorno escolar, amplía su autonomía de atención con los jóvenes en la construcción del conocimiento interdiscursivo.

Descriptores: Enfermería; Gente joven; Sexualidad; Tecnologías digitales

\section{Introdução}

O conceito de sexualidade é amplo e abrangente e se refere às manifestações de sentimentos, desejos, atitudes e percepções relacionados à vida afetiva, sexual, comunicação e ao vínculo entre as pessoas. A compreensão da sexualidade é a forma como as experiências são vividas e construídas em um processo contínuo na vida do indivíduo, por meio de uma aprendizagem constante permeada por concepções sociais, culturais e históricas. Para se entender a sexualidade, é necessário analisar a presença de aspectos repressivos e a internalização de padrões do que é considerado esperado e desejável. Logo, é importante considerar diversas instâncias como a família, a escola, o meio social, as religiões, os meios de comunicação entre outros aspectos. ${ }^{1}$

Foucault ${ }^{2}$ é visto como o historiador das proibições e do poder repressivo porque buscava o discurso das "verdades" produzidas e analisava como o poder que se exerce sobre a loucura e a sexualidade, produziu o discurso "verdadeiro" da psiquiatria e da sexologia respectivamente. Foucault ${ }^{3}$ afirmava que nas sociedades ocidentais, durante séculos, se ligou o sexo à busca da verdade, sobretudo, a partir do cristianismo. 
A sexualidade ao longo dos anos, vem sido discutida por meio de dispositivos institucionais com forte relação de poder junto ao público infanto-juvenil. Este processo intensifica e prolifera os discursos da sexualidade nas instituições como a igreja, escola, consultório médico, permitindo a vinculação e a intensificação dos poderes à multiplicação do discurso. $^{4}$

A articulação entre juventude e sexualidade vem despertando interesse de acadêmicos e gestores públicos nos últimos anos. ${ }^{5}$ A relação comumente estabelecida entre juventude e sexualidade passa, com cada vez mais vigor, por questões como gravidez precoce e prevenção das Infecções Sexualmente Transmissíveis - IST, as quais parecem se amparar, ainda que implicitamente, num enlace entre "juventude" e "risco", que se expressa no pressuposto de que a população jovem se encontraria mais propensa às práticas de um sexo inseguro. Como pano de fundo, a associação entre juventude, sexualidade e saberes, tem reiterado também a iniciação sexual como rito de mudança do corpo, da mente e cultural. ${ }^{6}$ Dessa forma, a configuração da sexualidade juvenil é atravessada por campos enunciativos diversificados.

Especificamente no Brasil, a inserção da educação sexual na escola se deu por meio de um deslocamento no campo discursivo sobre o assunto e nos anos 1920 e 1930, a discussão sobre educação sexual emergiu na escola em meio à epidemia de sífilis sendo que, naquele período, os problemas de “desvios sexuais" passaram a não mais ser percebidos como crime, e sim como doença. Por isso, a escola passou a constar entre os espaços de ação preventiva de uma medicina de caráter higienista, devendo cuidar da sexualidade de crianças e jovens, com vistas à produção de comportamentos tidos como "normais". ${ }^{7}$

Com os inúmeros avanços tecnológicos, a comunicação e informação em rede virtual têm influenciado na rapidez e contribuído com estas novas formas de cuidado em saúde para a população jovem escolar. O uso de recursos baseados no computador e na Internet assim como os sistemas de informação, tem se configurado como um processo de constantes mudanças e 
Cuidado de enfermagem na relação saber/poder e sexualidade junto a juventude...| 4

influenciado para prática de muitas profissões. Logo, a utilização de dispositivos como as Tecnologias Digitais de Informação e Comunicação - TDIC nos discursos da juventude sobre a sexualidade, trazem uma nova prática discursiva no cotidiano.

A presença das TDIC no cotidiano da enfermagem, principalmente no ambiente de trabalho por meio do cuidado educativo de enfermagem junto à juventude escolar, é indispensável e o seu desenvolvimento é inevitável, necessário e importante para o desenvolvimento da profissão e do cuidado humano. Essas tecnologias, quando adequadas e inteligentemente utilizadas e administradas, poderão beneficiar a prática do cuidado ao ser humano em múltiplas esferas. ${ }^{8}$

A saúde é considerada um dos setores mais dinâmicos em termos de absorção de novas tecnologias digitais. Na área da Enfermagem, as funções da informática podem ser utilizadas na assistência, assim como em atividades de promoção da saúde, com ênfase nas atividades de educação em saúde, reabilitação, prevenção e cura, assim como na pesquisa e no ensino. Diante disso, somando-se a popularidade das TDIC, essas se configuram como espaço privilegiado de relacionamento entre os jovens. Associar o uso destas tecnologias à saúde e educação tem instigado a atenção e promoção voltada à juventude, estimulando na escola a apropriação e disseminação de novos saberes e práticas em saúde no seu cotidiano entre pares. ${ }^{9}$

Identifica-se a necessidade de ampliar o olhar para a atuação do enfermeiro(a), quando se trata de questões de intervenção educativa com as culturas juvenis, pensando que outros territórios e linguagens são criados a partir do discurso, da subjetividade e das dúvidas por meio das TDIC, que tem o papel de agregar a relação de vinculação com os espaços virtuais na internet, sendo necessário fazer esta diferenciação.

A comunicação produzida com jovens das escolas por meio das vivências e reflexões elencadas, narradas e consolidadas com as intervenções nos territórios onde eles residem, sugere dobras com a formulação dos planos de cuidados que se funde à interação entre as 
demandas e discursos elaborados pelos jovens e os saberes dos enfermeiros. As dobras são os espaços do meio, onde a equipe da WebRádio, da Associação dos Jovens do Irajá - AJIR, transita. Com a visão das dobras, não se concebe o ambiente virtual em oposição ao espaço físico da escola, mas entende-se que a relação tempo-espaço é diferenciada. ${ }^{10}$

Assim, objetiva-se descrever a experiência de pós-graduandas de enfermagem sobre a sexualidade e a relação saber-poder junto à juventude escolar via WebRádio.

\section{Método}

Estudo descritivo, do tipo relato de experiência, que emergiu da vivência de mestrandas do Programa de Pós-Graduação Cuidados Clínicos em Enfermagem e Saúde da Universidade Estadual do Ceará - UECE, ao longo da disciplina de "Micropolítica”, realizada no primeiro semestre de 2016. Logo, veio a necessidade de descrever a vivência em relação à temática da sexualidade junto aos jovens escolares de cidades do sertão Nordestino, por meio de experimentações de discursos e cuidado educativo de enfermagem, com veiculação pela WebRádio AJIR, em articulação com referencial teórico-filosófico Saber/Poder de Foucault.

Experienciou-se das interações durante o programa entre os participantes (convidados expertises nos temas voltados para sexualidade junto à juventude escolar e os jovens escolares que estavam online) através do link: www.ajir.com.br, Facebook, Mural de Recados do site www.juventude.ajir.com.br, Whats $A p p$, e o arcabouço teórico de Foucault que apresenta em suas obras: a Microfísica do poder; ${ }^{2}$ As palavras e as coisas; ${ }^{3}$ História da sexualidade: a vontade de saber; ${ }^{4}$ as quais trazem uma hipótese repressiva sobre a sexualidade, em que argúi sobre as influências, há séculos, por uma cultura que incita o sexo em discurso como forma de poder.

A disciplina de micropolítica traz em seu contexto um grande estudo por parte desse referencial teórico e durante as aulas, os estudantes da pós-graduação (enfermeiros) são convidados a participarem da Webradio, trazendo suas experiências profissionais junto ao 
referencial teórico de Foucault para diálogo com os jovens sobre hipóteses repressivas sobre a sexualidade.

Assim, a experiência foi analisada possibilitando o agrupamento por afinidade da temática e apresentado em categorias: Web Rádio como ambiente virtual de produção de cuidado; Articulação do saber/poder/sexualidade e a subjetividade de jovens escolares através da ferramenta digital Web Rádio.

\section{Resultados e discussões}

Tem-se na vivência, primeiramente, a apresentação de uma cultura digital original que acontece no interior de práticas desenvolvidas em grupos e comunidades, uma vez que a WebRádio aparece tanto como ciberespaço de pertencimento e aprendizado de diferentes sujeitos, como também se constitui em espaço de trocas e convívios.

\section{WebRádio como ambiente virtual de produção de cuidado}

A WebRádio é um canal de comunicação digital online articulado entre a Associação dos Jovens de Irajá - AJIR com o Laboratório de Práticas Coletivas em Saúde - LAPRACS/CCS da UECE, com apoio da Pró-Reitoria de Extensão - PROEX, com registro no Conselho de Ensino, Pesquisa e Extensão da universidade, com o № 3175/2009. A WebRádio tem um estúdio na UECE em Fortaleza.

A emissora online está inserida em um projeto que envolve pesquisa, ensino e extensão com educandos do curso de Graduação e Pós-graduação de Enfermagem da UECE. O público principal dos programas da WebRádio são jovens escolares de duas escolas estaduais de Fortaleza/CE, assim como escolas de municípios do interior do Estado que são: duas escolas de Sobral, uma em Juazeiro, duas em São Benedito e uma em Guaraciaba. Também, mantém sua 
base de comunicação e mobilização comunitária em Irajá, distrito de Hidrolândia - Ceará, por meio da Biblioteca 21 de Abril.

Nesse canal de comunicação digital é apresentado o Programa "Em Sintonia com a Saúde”, para o qual são convidados especialistas nas diversas áreas da saúde. As demandas são sugeridas pelos territórios cadastrados no programa, as escolas. A WebRádio recebe as propostas, avalia, seleciona e estabelece a sua programação anual.

Dentre os profissionais participantes estão enfermeiros que dialogam sobre assuntos acerca da Saúde Reprodutiva, IST, Sexualidade, Gênero, Identidade, Contracepção, além de outros temas. Na sessão discursiva, os jovens debatem virtualmente no canal da WebRádio durante o programa e a equipe do estúdio trabalha para que as perguntas feitas pelos estudantes sejam transmitidas e respondidas pelo locutor e convidada, e que a imagem e o som cheguem de forma clara e acessível à recepção do programa na escola. Os participantes são orientados a acessarem o vídeo no centro do site, que se configura como uma saída da produção de imagens dos locutores em tempo real e transmissão de slides (ao vivo) em sala de vídeo ou multimeios, permitindo uma maior interação dos participantes, trazendo-os para dentro do canal com a convergência destas mídias e a possibilidades de outras participações, já que é um canal aberto na internet.

Na sessão discursiva, as "perguntas-discursos” são realizadas pelos alunos com dúvidas sobre o tema que está sendo apresentado no programa ao vivo as quais são utilizadas e armazenadas na página da rádio como fonte de material empírico para um diálogo ente o apresentador e o aluno. Nas interações (perguntas-discursos), há uma produção de perguntas que são substratos discursivos da juventude nas escolas. ${ }^{11}$

A programação do canal digital é diversificada, abordando temas de cultura, política, educação e saúde. O Programa Em Sintonia Com a Saúde (S@S) assume maior conteúdo interativo com o público juvenil de escolas públicas do Ceará que, semanalmente, discursavam sobre temáticas voltadas para a educação em saúde, assim como a promoção do cuidado (clínico) 
Cuidado de enfermagem na relação saber/poder e sexualidade junto a juventude... 8

educativo junto aos escolares, facilitada pelos bolsistas de enfermagem e alunos da Pósgraduação em Enfermagem. O programa acontece semanalmente, às quartas-feiras, ao vivo, às 16:00h, com 1 hora de interação com os participantes.

Sem a pretensão de encontrar uma resposta definitiva, nem oferecer uma verdade, preferiu-se usar neste estudo os termos “jovem” e “juventude”, ao invés de “adolescente”, uma vez que podem não se referir estritamente a uma faixa etária específica, nem a uma série de comportamentos reconhecidos. A escolha pelos termos “jovem” e "juventude" se expressam no sentido de que estes estão imersos em contextos culturais diversos, portanto, produz-se suas vidas mediadas pelos cotidianos de suas experimentações e vivências em grupos, entre outros territórios de produção de vida. ${ }^{12}$

O cuidado educativo de enfermagem junto à juventude ganha destaque, substituindo as práticas meramente campanhistas. Logo, são necessárias mudanças nas práticas de educação em saúde, pois elas se caracterizam pelo modelo hegemônico centralizado, vertical e unidirecional, orientadas pela difusão de conhecimentos. ${ }^{13}$

Neste sentido, o cuidado educativo, mediado pela comunicação e informação, vem sendo construindo no contexto da ciência da enfermagem, ao longo dos tempos, sob a acepção de aprimoramento da prática clínica. Para exercer a prática que hospeda esse objeto, o profissional necessita entender suas multidimensionalidades, seu caráter mutável e a potencialidade das ferramentas disponíveis, como no caso das ferramentas digitais, bem como o cenário em que permeia a produção desse tipo de cuidado, pois visa seu desenvolvimento com qualidade. $^{13}$

Unir o trabalho clínico e educativo da enfermagem com uso das TDIC, com vistas ao ensino de enfermagem, se revela como categorias analíticas e promissoras na prática clínica e educativa da enfermagem. Logo, é importante buscar estratégias que instiguem os estudantes de enfermagem a tais discussões, aliando do seu dia a dia ao cuidado em saúde. ${ }^{14}$ Destaca-se, 
também que as gerações atuais de jovens escolares consideram a tecnologia computacional algo natural. Assim, as atividades de educação em saúde podem ser otimizadas com a agregação da informática ao processo de trabalho da Enfermagem. ${ }^{9}$

O processo interativo e comunicativo entre público (jovens) e o convidado-debatedor ocorre de forma online pelo mural de recados do website da WebRádio (www.uece.ajir.com.br) e/ou pelos seus demais canais de acesso, como Facebook: WebRádio AJIR e WhatsApp. Nestas infovias, os jovens produzem perguntas e comentários desejando obter um esclarecimento e/ou explicação do tema em questão pelo enfermeiro ou outros profissionais de saúde convidados.

O programa pode ser acompanhado ao vivo, através da $W e b \mathrm{TV}$, possibilitando o contato visual permeado pela linguagem não verbal. Além disso, há a linguagem escrita, mediada pelos textos de interação entre a equipe de produção do programa e os internautas. E por último, há a linguagem verbal, produzida pelos discursos do entrevistador(a) e entrevistado(a). Assim, com as convergências das linguagens e das mídias sociais, os/as jovens interagem e buscam suas inquietações, questionamentos, dúvidas, sobretudo, criando um diálogo interativo entre todos os envolvidos no programa.

A leitura dos discursos é analisada a partir das manifestações de saúde dos jovens nos âmbitos da sexualidade. Em seu conjunto, nos aproximamos dos "estudos foucaultianos" (Microfísica do poder; ${ }^{2}$ As palavras e as coisas; ${ }^{3}$ História da sexualidade: a vontade de saber ${ }^{4}$ ), sobre discursos para situar os dizeres e os saberes dos participantes do estudo. ${ }^{15}$ É lançado mão do que vem sendo constituído como um enunciado discursivo (dito) e os diagramas o qual a mecânica de desejo constitui os modos dos sujeitos colocarem suas perguntas, que neste sentido se engendra em discursos acerca dos seus cotidianos de vida compondo, assim, o que denominamos de pergunta-discurso. ${ }^{15}$

O contexto dos estudos e pesquisas realizadas com utilização da WebRádio é aderente ao marco histórico do pós-estruturalismo. Esta tendência envolve princípios do desconstrutivismo, 
relativismo, conferindo aos textos uma pluralidade de sentidos em que a realidade é considerada como uma construção social e subjetiva. A abordagem é mais aberta no que diz respeito à diversidade de métodos. ${ }^{11}$

Localizar os sujeitos e suas expressões de subjetividades, de exposição, de vulnerabilidades, de produções positivas, de contatos cotidianos na escola e em outros ambientes de relações sociais nessa realidade da comunicação online, conectada diariamente à internet por meio do uso dos dispositivos, é uma tática para perceber, investigar e analisar as influências e repercussões que ser jovem provoca, desperta e gera inquietações, muitas vezes não sanadas no seio familiar ou em consultas com profissionais de saúde nos serviços físicos de saúde.

Também, como abordagem metodológica, as experimentações de uso do canal de comunicação digital têm ancoragem na perspectiva da educação problematizadora por meio das perguntas-discursos. Neste sentido, as atividades de ensino, pesquisa e extensão do projeto com sua prática discursiva crítica, instigam a desenvolver práticas problematizadoras que focam no educando, entendendo que este faz o seu próprio caminho no processo de ensino-aprendizagem. ${ }^{14}$

Sexo, sexualidade, educação sexual, preconceitos, discriminações sexuais, IST, gravidez precoce são algumas das questões que, recorrentemente, são acionadas nos discursos da juventude por meio da interação com a WebRádio. A sexualidade consiste em uma importante dimensão que atua na condução das condutas juvenis, a qual se articula também às questões de gênero e de subjetivação.

Tematizar a sexualidade juvenil requer atentar para as práticas discursivas no cotidiano. O conceito de prática discursiva implica que a linguagem é uma ação que produz efeitos. Ainda sobre tal concepção de discurso que aqui não se confunde com a fala, importa frizar que, na condição de prática, os discursos são originários e originam modos de relações sociais, produzem sujeitos, modos de existência e a própria experiência de si. Em A Ordem do Discurso, 
Foucault ${ }^{15}$ define prática discursiva como um conjunto de regras anônimas, históricas, sempre determinadas no tempo e no espaço que definiram, em uma dada época e para uma determinada área social, econômica, geográfica ou linguística, as condições de exercício da função enunciativa.

A comunicação gerada nos discursos pela importância do outro como sujeito que também produz o cuidado e que não apenas se objetiva nele, é uma forma de analisar a inovação na área da saúde ao encontro dos desafios que a sociedade contemporânea "cobra”, impulsionando os profissionais à tessitura de planos que atendam as demandas dos mais diversos territórios, fissurando as barreiras físicas, geográficas, partindo em direção aos múltiplos brasis e diferentes culturas em territórios vivos. ${ }^{10}$

As práticas discursivas correspondem aos momentos ativos de uso da linguagem, aos modos a partir dos quais jovens compõem sentidos e se posicionam em relações sociais no cotidiano por meio da WebRádio. Sob esse prisma, os sentidos são aqui compreendidos como acontecimentos resultantes de negociações nas práticas discursivas, entendendo que sua produção se dá pelo confronto de vozes sociais que precedem e perpassam a construção de todo e qualquer enunciado.

\section{Articulação do saber/poder/sexualidade e a subjetividade de jovens escolares através da ferramenta digital WebRádio AJIR}

A sexualidade é a forma cultural pela qual se vive os desejos e prazeres corporais e consiste, em importante marca da subjetividade juvenil. ${ }^{1}$ A juventude é convocada a exercer uma série de técnicas de si, para se autoconhecer, produzir um "eu” de determinado modo, corrigir aquilo que não está de acordo com as normas vigentes e produzir uma nova subjetividade. Ao mesmo tempo, a juventude é constantemente alvo de técnicas de dominação que atuam na condução da conduta juvenil. A produção da subjetividade se dá no ponto de contato dessas técnicas, as quais atuam no autogoverno e no governo das/os outras/os. ${ }^{2}$ 
Ao considerar o olhar para os programas de disseminação das TDIC, compreende-se que as práticas discursivas são operacionalizadas por meio das ferramentas digitais e que tais instrumentos são localizados no tempo, espaço e conforme o contexto social, econômico e político de cada época. ${ }^{15}$

As mídias digitais, no caso a WebRádio AJIR, é uma ferramenta utilizada neste estudo e tem mediado esse processo de educação em saúde, favorecendo a aproximação dos serviços de saúde aos jovens e às escolas com temas problemas da atualidade na saúde no Brasil.

Em vista disso, é possível identificar que a ferramenta de cuidado WebRádio AJIR se encontra inserida neste contexto de propulsão ao discurso do sexo que se apresenta em nossa sociedade há mais de três séculos. Logo, são realizadas cartografias das problematizações das perguntas-discursos discutidas sobre a sexualidade produzida na WebRádio com jovens escolares. Cartografar as discursões juvenis significa que as perguntas-discursos que se apresentam como ditos e não ditos em torno deste tema apresentam como inovação, regulação e repetição do que, historicamente, se diz e se afirma sobre sexo e sexualidade, como um saber de verdade, um saber a ser seguido, aceito e praticado. ${ }^{11}$

A vantagem de estar inserido à juventude escolar e a oportunidade de conhecer e discutir com uma variedade de pessoas com problemas ou objetivos semelhantes em que o fato de poder compartilhar preocupações comuns faz com que haja uma variedade de feedback que não seria possível individualmente. E nas vivências dos territórios de saúde foi visto de forma clara que a discussão geral das plenárias estava voltada para a sexualidade.

A escola é um espaço privilegiado na implantação de ações que promovam o fortalecimento da autoestima e do autocuidado, a preparação para a vivência democrática, o aumento dos níveis de tolerância às diversidades, o respeito mútuo e, desta forma, a melhoria da qualidade de vida. É um lugar fundamental para se discutir o tema sexualidade, logo a 
sexualidade envolve além do corpo, histórias, costumes, relações afetivas, cultura. Falar de sexualidade é falar da própria vida.

Com efeito, a escola se configura como local dos mais importantes para programar propostas com uso de metodologias novas, como as TDIC nas discussões que abranjam a população juvenil. Não são, senão, tais preocupações sociais envolvendo como problema demográfico, e as IST que justificam a inclusão de temas ligados à sexualidade em propostas curriculares, especialmente nos últimos anos.

Nos últimos anos, a sexualidade nos jovens mais do que uma questão moral, adquiriu uma dimensão de problema social, sendo inclusive vista como um problema de saúde pública. Entre inúmeras questões que poderiam ser tratadas no que concerne a essa temática, despontam como prioridade pontos como gravidez não planejada, IST, culminando no destaque de instruções preventivas para o "sexo consciente" e o uso de preservativo. ${ }^{16}$

A Enfermagem também adentra nessa unidade e cenário escolar, por meio das práticas de educação em saúde, na aproximação com o jovem para ouvir e permitir que falem sobre esta sexualidade.

Nas sessões sobre a sexualidade foram identificados nas discussões, que os jovens citavam a gravidez não planejada como um evento comum. Jovens iniciam precocemente sua vida sexual embora desconheçam a estrutura fisiológica reprodutiva de seus corpos, como no caso do período fértil, podendo desestabilizar suas vidas. ${ }^{16}$

Observa-se nas perguntas-discursos da juventude escolar, um universo de palavras como a camisinha, namoro, corpo, proibido, não proibido, gênero, identidade, família, escola, gravidez não planejada, IST/HIV/Aids. Assim, a WebRádio permitiu uma rica discussão com escolares sobre a sexualidade e realidade cotidiana. Os jovens mencionam, ainda, a dificuldade de conversarem com seus pais sobre namoro e sexo, mencionando como algo proibido por não ser o momento, mesmo convivendo com amigos que já são pais, mães ou colegas que estão grávidas. 
Segundo Foucault, ${ }^{4}$ a sexualidade não é aquilo que o poder tem medo, mas aquilo que se usa para seu exercício. As proibições não são formas essenciais do poder, são apenas seus limites, as formas frustradas.

Os jovens são provocados a falar e a falar cada vez mais sobre sua sexualidade. Sua vivência passa por uma avaliação do pai e da mãe que finge não estar avaliando para poder saber mais, senão o(a) filho(a) pode recuar e calar. Saber esse que lhe dá poder para "orientar" da forma que considerar mais "útil” para o futuro do(a) filho(a). Essa "utilidade” quase sempre está mais ligada a um funcionalismo do que a um prazer ao qual o(a) filho(a) possa almejar. ${ }^{3}$

Isto posto, reitera-se que o jogo de poder existente na relação apresentada por esses pais não consiste em demarcar o certo ou errado, o lícito ou ilícito, e, muito menos, implica em algum tipo de condenação. A ordem agora é gerir a sexualidade dentro de um sistema de utilidade. Assim, o sexo não se julga, administra-se. Mas, nesse jogo de relações, não deve haver condenações, os pais também estão tentando "funcionar", e funcionar aqui tem um sentido de estar colaborando para que uma engrenagem maior, da qual se sentem apenas uma peça, funcione. ${ }^{4}$

A juventude, por sua vez, tem incorporado o universo digital como canal para discutir saúde na escola e fora dos seus muros. Contudo, o profissional de saúde deve lançar mão de recursos que busquem o envolvimento do público jovem nos serviços, trazendo estes para um novo foco. sem lhes tirar do seu meio de interesses. ${ }^{11}$

Outra temática relevante abordada foi o discurso na escola e na família sobre a homossexualidade. Muitos mencionaram que tem vários amigos gays, lésbicas e travestis mas, muitas vezes, escondem de seus pais com medo das represálias. Outros ainda citaram que são homossexuais e outros não sabem sua escolha sexual e se sentem constrangidos ao falarem para os pais e professores, preferindo desabafar com amigos ou colegas. 
Foucault ${ }^{2}$ enfoca a questão da homossexualidade ponderando que, em torno de 1870 , os psiquiatras passaram a considerá-la como objeto de análise médica, ponto de partida para a introjeção de novas intervenções e controles. Os homossexuais passaram, assim, a ser percebidos como loucos ou doentes do instinto sexual. Antes, eram considerados libertinos ou delinquentes. Surge, então, a invenção estratégica da "mesma" como vontade de verdade.

O mesmo acontece com as demais minorias: a mulher, o negro, índio, quilombola entre outros seguimentos. Alguns mecanismos levam à patologização da mulher ao considerar seu sexo frágil, quase doente, frígida, entre outros. As meninas também mencionaram que, tanto na escola como em casa, há uma diferença entre o menino e a menina quando o assunto é sexualidade, namoro e relação sexual. Relataram a proibição do namoro e sexo por serem mulheres, podendo manchar seus nomes na sociedade.

O diálogo sobre discriminação de gênero e orientação sexual na família e educação, tem alcançado um alto grau de qualidade e respeitabilidade internacional e fornece diagnósticos que apontam a escola brasileira como um importante espaço de reprodução de modelos particularmente autoritários, preconceituosos e discriminatórios em relação a mulheres e homossexuais, entre outros grupos. Os movimentos feministas problematizaram estes estereótipos das mulheres, ou seja, estes discursos de regulação de seus modos de vida aceitam o desafio ao assumirem a reinvenção de seu próprio tipo de existência, partindo da sexualidade que as aprisionam para se direcionarem a outras afirmações. ${ }^{17}$

A sexualidade e as escolhas sexuais continuam sendo um assunto delicado e difícil. É uma área na qual se encontram as inseguranças e o medo com relação ao outro. Conversar sobre sexo requer uma relação de intimidade e confiança. A sexualidade é tema que cada vez mais deve fazer parte da discussão entre pais, filhos, educadores e profissionais de saúde, logo é uma forma de diminuir a falta de informação e o desconhecimento sobre a mesma, estabelecer valores, estimulando o conhecimento de si e do outro. ${ }^{18}$ 
Em seus discursos, os jovens mencionaram também que a escola é um lugar interessante, de paixões, desejos e descobertas mas, na maioria das vezes, não tem um diálogo aberto com professores sobre dúvidas, medos, angústias, mudanças corporais, desejos e identidade sexual. Relataram que a maioria dos professores ficam fechados em seus mundos de conteúdos superficiais da realidade do cotidiano escolar e, devido à essas atitudes, os jovens silenciam suas falas.

A pedagogia da sexualidade que é exercida na escola, seja pela afirmação ou pelo silenciamento, nos espaços públicos ou nos cantos escondidos e privados, legitima determinadas identidades e práticas sexuais, reprimindo e marginalizando outras. ${ }^{17}$

Foram vistas nas falas que profissionais de saúde vão pouco ao ambiente escolar e a categoria que mais está presente nesse cenário são enfermeiros veiculados pela WebRádio. A Enfermagem tem uma atuação com relevância social e humanística, e as tecnologias digitais vêm se inserindo em sua prática clínica e no seu processo de cuidar, uma vez que a enfermagem precisa lançar mão de recursos que busquem o envolvimento do público juvenil nos mais variados espaços.

As perguntas da juventude enfatizam que os temas debatidos pelos profissionais de saúde e professores são pontuais. Muitos discutem sobre a sexualidade, prevenção, contracepção e gravidez por meio de palestras, enfatizando os problemas e as doenças. Não problematizam realidades, casos de gravidez, estrupo, violência sexual, pedofilia, bullying, identidade sexual, promoção da saúde e diversidade cultural existente no universo escolar, muitas vezes, mascarados e silenciados, consequentemente, não criando vínculo com professores e profissionais de saúde.

A sexualidade é constantemente saturada, ou seja, dita, excitada, para que haja a produção de desejo, no entanto, é alertado que elas são vividas e afirmadas dentro de um campo de saber e poder, que gera formas de verdades e dá lugar aqueles que detêm do saber/poder em seus modos de prescrição e regulação, por exemplo, médicos, psicólogos, sexólogos, etc. ${ }^{2}$ 
Os jovens, durante as sessões da WebRádio, mencionaram a necessidade de espaços para o compartilhamento dessas informações e escuta, além da criação de estratégias para difusão da informação acerca da sexualidade, atividades estas específicas para a juventude, em que eles possam ser protagonistas das ações, estabelecendo vínculo com profissionais de saúde e professores(as), proporcionando a educação e saúde na escola.

Neste cenário, o uso de novas TDIC na educação em saúde, surge como um forte instrumento da enfermagem que vem atuando com o público juvenil escolar em atividades de para o cuidado inovador e interativo em saúde. Assim, o debate sobre a sexualidade por meio de ferramentas digitais como a WebRádio, necessita de estímulo e incentivo para as juventudes, pois é necessário que se criem vínculos e que eles participem ativamente como protagonistas da construção do próprio conhecimento e agreguem dinamismo, reflexão e cuidado de si.

\section{Considerações finais}

Os caminhos possibilitaram realizar esta viagem produzida nas dobras dos territórios virtuais, em contato com jovens cheio de desejos, curiosidade e dúvidas. Esse percurso culminou com a vivência quanto à utilização do dispositivo de comunicação a WebRádio como uma rede interdiscursiva que proporciona interações dialógicas com a juventude quanto à sua sexualidade, utilizando como espaço de poder para que estes possam desenvolver o cuidado de si.

Foi possível observar, a partir dos estudos filosóficos de Foucault, que os discursos não se referem apenas ao que é dito, ao conteúdo expresso, mas aquilo que nomeia e viabiliza as vontades de verdade. Os saberes não se referem ao que é tido como ciência, mas ao que é produzido na dinâmica dos dispositivos dos discursos de verdade.

No tocante à discussão do tema, há ausência do discurso professor(a)/enfermeiro(a)/juventude ou a imposição de temas sobre a sexualidade, sem adentrar nas realidades experiênciadas pela juventude escolar. Logo, é necessário que seja discutida a 
temática junto aos jovens de maneira diferenciada, em substituição à forma imposta com a qual é apresentada e que se priorize a participação dos pais e professores, em uma abordagem que não apenas trate das questões da gravidez, IST, contracepção, mas também que se destaquem as questões de sociais e saúde.

Embora ocorram ações educativas ainda são pouco abrangentes no que se refere a esse assunto. É visto ainda a dificuldade do envolvimento da enfermagem em relação a temas como a sexualidade no cenário escolar, apresentando se de maneira tímida. Aponta-se a necessidade de educação permanente em saúde de enfermeiros que possibilitem o conhecimento sobre o tema criando, assim, espaço de diálogo nas instituições de ensino, na assistência e comunidade.

A utilização das TDIC como no caso da WebRádio, colabora com o cuidado educativo de enfermagem de maneira singular no se relacionar com o outro. Embora na vivência não se tenha como "controlar" as reverberações das narrativas de si e do outro, produzidas no contexto do grupo de discussão, a experiência apresenta que novos posicionamentos podem ser construídos mais efetivamente quando num espaço de problematização, os jovens vivem a possibilidade de narrá-los, de expressá-los sem tantas censuras. Dessa forma, a escola se configurou como espaço de resistência.

Deste modo, a experiência contribui aos novos olhares sobre a sexualidade e os dispositivos virtuais, tendo em vista serem instrumentos poucos abordados nas escolas. Também se chama a atenção dos enfermeiros quanto à importância da aproximação com a juventude para criação de vínculo e confiançam, necessários para a expressão de seus sentimentos e modos de verdades sobre a sexualidades e suas relações cotidianas de produção de si.

A produção de trabalhos utilizando referencial teórico-filosófico permitiu embasamento e enriquecimento da enfermagem enquanto ciência, por isso se reforça a utilização de filósofos como Foucault que permitem adentrar nesta subjetividade. A Enfermagem se integra nesta construção histórica moderna, neste campo das sexualidades que deve ser pensando no seu 
modo de ver, escutar, de emprestar sua lente de análise para as demandas dos discursos dos jovens e dos modos de cuidar de si.

Portanto, avaliou-se que o grupo de discussão foi relevante por meio da WebRádio, dispositivo de análise coletiva nas escolas, compatibilizando o aprofundamento de informações com a problematização do cotidiano. A propósito, as discussões sobre "sexualidade" oportunizadas pela vivência, contribuíram para que questões indiscutíveis sobre o tema viessem à tona naquele cenário. Igualmente, serviu para problematizar o que era concebido pela juventude como algo natural, não só relativo aos sentidos sobre o assunto, mas inclusive com relação às próprias ações educativas em saúde que lhes eram direcionadas, dentro e fora da escola.

Neste sentido, é necessário prosseguir na realização de novas vivências por meio do cuidado educativo de enfermagem ancorado em um saber filosófico, por permitir a apropriação do referencial teórico e vivenciar um dispositivo virtual com este propósito e com o qual se experiencia alguns desencaixes, tensões e desafios, porém absortos por ricas e profundas vivências e aprendizagens.

\section{Referencias}

1. Farias PAM, Martin ALAR, Cristo CS. Aprendizagem ativa na educação em saúde: percurso histórico e aplicações. Rev Bras Educ Méd. 2015 [acesso em 2019 mar 11];39(1):143-50. Disponível em: http://www.scielo.br/pdf/rbem/v39n1/1981-5271-rbem-39-1-0143.pdf

2. Foucault M. Microfísica do poder. 3ª ed. Rio de Janeiro: Paz e Terra; 2015.

3. Foucault M. As palavras e as coisas: uma arqueologia das ciências humanas. 10ª ed. São Paulo: Martins Fontes; 2016.

4. Foucault M. História da sexualidade: a vontade de saber. 8ª ed. Rio de Janeiro: Graal; 2015.

5. Sfair SC, Bittar M, Lopes RE. Educação sexual para adolescentes e jovens: mapeando proposições oficiais. Saúde Soc [Internet]. 2015 [acesso em 2019 mar 11];24(2):620-32. Disponível em: http://www.scielo.br/pdf/sausoc/v24n2/0104-1290-sausoc-24-02-00620.pdf 
6. Couto Junior DR, Oswald MLMB, Pocahy FA. Gênero, sexualidade e juventude(s): problematizações sobre heteronormatividade e cotidiano escolar. Civitas [Internet]. 2018 [acesso em em 2019 mar 10];18(1): 124-37. Disponível em: http://www.scielo.br/pdf/civitas/v18n1/1519-6089-civitas-18-01-0124.pdf

7. Furlanettoi MF, Lauermannii F, Costa CB, Mariniv AH. Educação sexual em escolas brasileiras: revisão sistemática da literatura. Cad Pesqui [Internet]. 2018 [acesso em 2019 mar 11];48(168):550-71. Disponível em: http://www.scielo.br/pdf/cp/v48n168/1980-5314-cp-48-168-550.pdf

8. Santos MP, Farre AGMC, Bispo MS, Sousa LB, Marinho DDT. Promoção da saúde sexual e reprodutiva de adolescentes: educação por pares. Rev Baiana Enferm. 2017 [acesso em 2019 mar 11];31(3): 21505. Disponível em: https://portalseer.ufba.br/index.php/enfermagem/article/viewFile/21505/15031

9. Moreira TMA, Sousa DF, Silva SET, Santana WJ, Luz DCRP. O papel do enfermeiro na assistência prestada às adolescentes grávidas. Rev e-Ciênc. 2016;4(1):43-53.

10. Souza VEC. Desenvolvimento e validação de software para apoio ao ensino-aprendizagem sobre diagnósticos de enfermagem [tese]. Fortaleza: Universidade Federal do Ceará; 2015 [acesso em 30 set 2017]; Programa de Pós-Graduação em Enfermagem (PPE). Disponível em: http://www.repositorio.ufc.br/bitstream/riufc/12557/1/2015_tese_vecsousa.pdf

11. Torres RAM, Abreu LDP, Araújo AF, Veras KCBB, Oliveira GR, Tavares NBF, et al. Promotion of webcare in nursing through a WebRadio: knowledge of schoolageyouthon collective health themes. Int J Develop Res [Internet]. 2019 [acesso em 2019 mar 11];9(2):25661-6. Disponível em: http://www.journalijdr.com/sites/default/files/issue-pdf/15243.pdf

12. Abreu LDP, Torres RAM, Silva MRF, Araújo AF. Web radio como ferramenta de diálogo em saúde coletiva no sertão: juventudes e métodos contraceptivos. SANARE Sobral. 2018;17(1): 24-31.

13. Krysia WH, Marion JB. O desafio da enfermagem e da saúde na idade digital. Texto \& Contexto Enferm [Internet]. 2018 [acesso em 2019 set 14];27(2). Disponível em: http://www.scielo.br/scielo.php?script=sci_arttext\&pid=S0104-07072018000200100\&lng=en. Epub June 21, 2018. http://dx.doi.org/10.1590/0104-07072018002018editorial2

14. Torres RAM, Silva MDM, Bezerra AEM, Abreu LDP, Mendonça GMM. Comunicação em saúde: uso de uma web rádio com escolares. J Health Inform [Internet]. 2015 [acesso em 2016 maio 21];7(2):58-61. Disponível em: http://www.jhi-sbis.saude.ws/ojs-jhi/index.php/jhi-sbis/article/viewFile/325/233

15. Foucault M. A ordem do discurso. São Paulo: Loyola; 2018.

16. Torres RAM, Melo CB, Abreu LDP, Veras KCBB. Saberes dos estudantes de enfermagem sobre a saúde da população LGBT debatidos via web rádio. TICS \& EAD em Foco. 2018;4(41):41-57.

17. Morais EV, Toledo OR, David FL, Avelino MM, Campos RN. Gravidez na adolescência e aborto: implicações da ausência de apoio familiar. Rev Adolesc Saúde. 2017;14(3):41-7. 
18. Nery IS, Feitosa JJM, Sousa AFL, Fernandes ACN. Abordagem da sexualidade no diálogo entre pais e adolescentes. Acta Paul Enferm [Internet]. 2015 [acesso em 2019 mar 11];28(3):287-92. Disponível em: http://www.scielo.br/pdf/ape/v28n3/1982-0194-ape-28-03-0287.pdf

\section{Autor Correspondente}

Leidy Dayane Paiva de Abreu

E-mail: dayannepaiva@hotmail.com

Endereço: Campus do - Av. Dr. Silas Munguba, 1700 - Itaperi, Fortaleza - CE.

CEP: 60741-000

\section{Contribuições de Autoria}

\section{1 - Leidy Dayane Paiva de Abreu}

Contribuições: concepção, coleta, análise e interpretação dos dados do manuscrito.

\section{2 - Glícia Mesquita Martiniano Mendonça}

Concepção, coleta, análise e interpretação dos dados do manuscrito.

\section{3 - Aretha Feitosa de Araújo}

Análise, interpretação dos dados do manuscrito e revisão crítica do manuscrito..

\section{4 - Raimundo Augusto Martins Torres}

Redação e revisão crítica do manuscrito.

\section{5 - Maria Rocineide Ferreira da Silva}

Redação e revisão crítica do manuscrito.

\section{6 - Ana Virgínia de Melo Fialho}

Redação e revisão crítica do manuscrito.

\section{Como citar este artigo}

Abreu LDP, Mendonça GMM, Araújo AF, Torres RAM, Silva MRF, Fialho AVM. Cuidado de enfermagem na relação saber/poder e sexualidade junto a juventude escolar via webrádio. Rev. Enferm. UFSM. 2019 [Acesso em: Anos Mês Dia];vol9: e54: P1-21. DOI:https://doi.org/10.5902/2179769233663 